\title{
Anthocyanins potentiate the activity of trastuzumab in human epidermal growth factor receptor 2-positive breast cancer cells in vitro and in vivo
}

\author{
WEIHUA LIU ${ }^{1}$, JINMEI XU ${ }^{1}$, YILUN LIU ${ }^{1}$, XIAOPING YU ${ }^{2}$, XI TANG ${ }^{1}$, ZHI WANG ${ }^{1}$ and XIN LI ${ }^{3}$ \\ ${ }^{1}$ Department of Scientific Research, First Affiliated Hospital of Chengdu Medical College, Chengdu, Sichuan 610500; \\ ${ }^{2}$ Department of Public Health and ${ }^{3}$ Administrative Office, Chengdu Medical College, Chengdu, Sichuan 610500, P.R. China
}

Received March 5, 2014; Accepted June 17, 2014

DOI: $10.3892 / \mathrm{mmr} .2014 .2414$

\begin{abstract}
Human epidermal growth factor receptor 2 (HER2) has been found to be overexpressed in $25 \%$ of invasive breast cancer and is significantly associated with a poor prognosis in breast cancer patients. The anthocyanins cyanidin-3-glucoside $(\mathrm{C} 3 \mathrm{G})$ and peonidin-3-glucoside have been identified as potential drugs for the therapy of HER2-positive breast cancer. They have been used as supplements in targeted therapeutics and chemotherapeutics in Asia, however, the underlying mechanism remains to be elucidated. The aim of the present study was to investigate the synergism between $\mathrm{C} 3 \mathrm{G}$ and trastuzumab (Trast). To address this question, the response to $\mathrm{C} 3 \mathrm{G}$, Trast and a combination of the two drugs, in three representative HER2-positive cell lines was evaluated. The combination treatments induced apoptosis, inhibited cell growth and affected HER2 and its downstream signaling pathway in MDA-MB-453, BT474 and HCC1569 cells, and the effects were synergistic. The combination of 3CG and Trast inhibited tumor growth in an in vivo xenograft model. The data from the present study suggested that $\mathrm{C} 3 \mathrm{G}$ exhibits potent antitumor activity when combined with Trast under the investigated conditions.
\end{abstract}

\section{Introduction}

Breast cancer is a life-threatening disease and is the most common type of malignancy in Western countries. An estimated 232,340 new cases of invasive breast cancer were expected to be diagnosed among females in the USA during 2013 according to the American Cancer Society (1). In China, breast cancer accounts for $\sim 7-10 \%$ of all types of malignant

Correspondence to: Dr Xin Li, Administrative Office, Chengdu Medical College, 783 Xindu Road, Chengdu, Sichuan 610500, P.R. China

E-mail: xinlijournal@live.com

Key words: anthocyanins, cyanidin-3-glucoside, synergism, drug combination tumor, with a 3-4\% increase in new cases each year (2). Evidently, there is a clear requirement for the development of new therapeutic agents.

Overexpression of human epidermal growth factor receptor 2 (HER2), also termed erbB2, occurs in $20 \%$ of patients with breast cancer and is associated with aggressive disease and a decreased survival rate. Currently, chemotherapy and targeted anti-cancer drugs, including tyrosine kinase inhibitors and monoclonal antibodies, such as trastuzumab (Trast) (3) have been demonstrated to be effective in clinical settings. The underlying mechanism of Trast binding to domain IV of the extracellular segment of the HER2 receptor and leading to the G1 arrest of HER2positive cancer cells has been investigated. Since 2000, the disease-free survival rate and overall survival rate of patients have improved significantly (3-6). Traditional Chinese herbal medicines have been used for $>3,000$ years and there are reports of novel therapeutic approaches using traditional medicine being successful in breast cancer patients $(7,8)$. Although thousands of traditional Chinese medicines have been verified to be clinically effective, the mechanisms underlying the drug actions remain to be elucidated. Our previous study examined a high-throughput in vitro screen against a library of 10,000 natural products in six cell lines representing breast cancer and assessed the ability of each drug to cause cytotoxicity. A total of eight natural compounds were identified as selectively inhibiting the proliferation of HER2-positive cells. Two of the compounds were confirmed as peonidin-3-glucoside (P3G) and cyanidin-3-glucoside (C3G) in vitro and in vivo (9).

$\mathrm{P} 3 \mathrm{G}$ and $\mathrm{C} 3 \mathrm{G}$ are anthocyanin pigments extracted from black rice (10). $\mathrm{P} 3 \mathrm{G}$ and $\mathrm{C} 3 \mathrm{G}$ possess anti-cancer properties and have been used as medicine or as supplements for numerous decades (11-16). P3G and C3G inhibit phospho-HER2 and phospho-AKT and were confirmed to induce HER2-positive breast cancer cell apoptosis in vitro (9). In vivo studies were also conducted to confirm the antitumorgenic effects of $\mathrm{P} 3 \mathrm{G}$ and $\mathrm{C} 3 \mathrm{G}$ (9).

These established results have led to the hypothesis that P3G or C3G may function with the anti-HER2 drug, Trast, in a synergistic way. Therefore, the present study investigated the combined anti-tumor effects of P3G and C3G with Trast on 
representative HER2-positive breast cancer cell lines and on a tumor xenograft model.

\section{Materials and methods}

Chemicals. Unless otherwise stated, all chemicals and reagents (analytical grade) were purchased from Sigma-Aldrich (Shanghai, China). Trast was provided by the Pharmacology Department of Chengdu Medical College (Chengdu, China) with a $>98 \%$ purity. $\mathrm{P} 3 \mathrm{G}$ and $\mathrm{C} 3 \mathrm{G}$ were purchased from Pharmanic (Sichuan, China) with $>98 \%$ purity. Compounds were present in dimethyl sulfoxide and stored at $-80^{\circ} \mathrm{C}$ prior to use.

Cell culture. All cell lines were obtained from the American Type Culture Collection (Manassas, VA, USA). MDA-MB-453 cells were maintained in Dulbecco's modified Eagle's medium (DMEM) containing $2 \mathrm{mmol} / 1 \mathrm{~L}$-glutamine. BT474 cells were maintained in DMEM:Ham's F12 medium (1:1 mixture) containing $2 \mathrm{mmol} / \mathrm{l} \mathrm{L}$-glutamine and $5 \mu \mathrm{g} / \mathrm{ml}$ insulin. HCC1569 cells were maintained in RPMI-1640 medium. All mediums were supplied with $10 \%$ fetal bovine serum and $1 \%$ penicillin/streptomycin. All cells were maintained in a $5 \%$ $\mathrm{CO}_{2}$ atmosphere at $37^{\circ} \mathrm{C}$.

Cell proliferation assay. Cell proliferation assays were performed, as described previously (9). The cells were cultured for 24,48 or $72 \mathrm{~h}$ at $37^{\circ} \mathrm{C}$ in a $5 \% \mathrm{CO}_{2}$ atmosphere with or without $\mathrm{C} 3 \mathrm{G}$, Trast or the combination. Aliquots of Alamar-Blue reagent were added directly to each well and the plates were incubated at $37^{\circ} \mathrm{C}$ for $3 \mathrm{~h}$. The fluorescent signal was measured on a ZS-2 plate reader (Hongrunda, Beijing, China) with an excitation at $530 \mathrm{~nm}$ and emission at $590 \mathrm{~nm}$. Data were normalized as percentage viability relative to vehicle controls, defined as $100 \%$ survival. The combination index values were calculated using CalcuSyn V2.1 software (Biosoft, Cambridge, UK).

Western blot analysis. Western blot analysis was performed as previously described (9) with the following antibodies: anti-phospho HER2 (Tyr1248; monoclonal, anti-rabbit), anti-HER2 anti-phospho AKT (Thr308 or Ser473; monoclonal, anti-rabbit), anti-AKT (monoclonal, anti-rabbit), anti-phospho p42/44mitogen activated protein kinase (MAPK; monoclonal, anti-mouse), anti-p42/44MAPK (monoclonal, anti-mouse) and anti- $\beta$ actin (monoclonal, antimouse) antibodies (Shanghai Rui Qi Biological Technology Co., Shanghai, China).

Annexin V-fluorescein isothiocyanate (FITC) assay. The early apoptotic effects of drug treatment were assessed by an Annexin V-FITC assay, as described previously (9). Cells were treated with or without $\mathrm{C} 3 \mathrm{G}$, Trast or the combination for $24 \mathrm{~h}$ at $37^{\circ} \mathrm{C}$. Cells were stained with an Annexin-V-FITC antibody supplied by the Chengdu Medical College Flow-cytometry Core Facility. Bivariant analysis of FITC fluorescence and propidium iodide (PI) fluorescence revealed different cell populations, where FITC (-) and PI (-) were designated as viable cells, FITC (+) and PI (-) as apoptotic cells and FITC (+) and PI (+) as late apoptotic or necrotic cells.
Caspase 3/7 activity assay. The apoptotic effects of drug treatment were assessed by a caspase 3/7 activity assay, as described previously (9). After $48 \mathrm{~h}$ drug treatments, aliquots of Alamar-Blue reagent were added directly to each well, the plates were incubated at $37^{\circ} \mathrm{C}$ for $3 \mathrm{~h}$ and the fluorescent signal was recorded. An equal volume of caspase 3/7 activity assay reagent (Promega, Bejing, China) was then added to each well and the luminescence signal was measured using the ZS-2 plate reader. Caspase 3/7 activities were normalized as luminescence relative to fluorescence.

In vivo efficacy in xenograft models. In accordance with the Institutional Guidelines of the Chengdu Medical College Institutional Animal Care and Use Committee (IACUC), all in vivo studies were performed under pathogen-free conditions at the animal facility and methods were reviewed and approved by the IACUC. BT474 cells were resuspended to $2 \times 10^{6}$ cells $/ 100 \mu \mathrm{l}$ in phosphate-buffered saline (PBS) and implanted subcutaneously into the flank region of 6-7-week old female nude mice weighing 18-22 g, as described previously (9). When tumors reached $40-50 \mathrm{~mm}^{3}$ in volume, animals were randomly assigned to four groups $(n=8)$, receiving either intraperitoneal (IP) injection of $100 \mu \mathrm{l}$ PBS twice a week; IP injection of $\mathrm{C} 3 \mathrm{G}(6 \mathrm{mg} / \mathrm{kg}$ in $100 \mu \mathrm{l}$ PBS $)$ twice a week; IP injection of Trast $(6 \mathrm{mg} / \mathrm{kg}$ in $100 \mu \mathrm{l}$ PBS $)$ twice a week or Trast and C3G (6 mg/kg of Trast and C3G in $100 \mu \mathrm{l}$ PBS) twice a week. Tumor volume was measured every 5 days and, once the control tumors reached $1,000 \mathrm{~mm}^{3}$, the animals were sacrificed in accordance with ethical requirements. At the end of the study, all animals were sacrificed with an overdose of $\mathrm{CO}_{2}$ and the tumor tissues were extracted for immunostaining and weighing.

Statistical analysis. In vitro data are expressed as the mean \pm standard deviation $(\mathrm{n} \geq 3)$. In vivo data are expressed as the mean \pm standard error of the mean $(n=8)$. Values were analyzed using Student's t-test or one-way analysis of variance when three or more groups were present using SigmaPlot V.11.0 (Systat Software Inc., San Jose, CA, USA). $\mathrm{P} \leq 0.05$ was considered to indicate a statistically significant difference.

\section{Results}

$C 3 G$ demonstrates synergy in combination with Trast in HER2-positive breast cancer cells. The role of $\mathrm{C} 3 \mathrm{G}$ in combination with Trast on cell proliferation and survival was investigated by performing cell viability assays. Cells were treated with either $20 \mu \mathrm{g} / \mathrm{ml}$ Trast, $1 \mu \mathrm{g} / \mathrm{ml} \mathrm{C} 3 \mathrm{G}$ or a combination for up to 24 or $48 \mathrm{~h}$. All cell lines demonstrated inhibition of growth after $24 \mathrm{~h}$ treatment (Fig. 1A-C) and after $48 \mathrm{~h}$ treatment (Fig. 1D-F). The percentage of viable cells in the combination treatment groups in MDA-MB-453, BT-474 and HCC1569 cells were significantly lower compared with either Trast alone or the $\mathrm{C} 3 \mathrm{G}$ alone treatment groups after 24 and $48 \mathrm{~h}$ (Fig. 1A-F). In order to investigate the synergism between $\mathrm{C} 3 \mathrm{G}$ and Trast, combination cell viability assays were performed and the combination index (CI) values were determined using the CalcuSyn software (Biosoft). All combinations demonstrated synergism in the three cell lines 


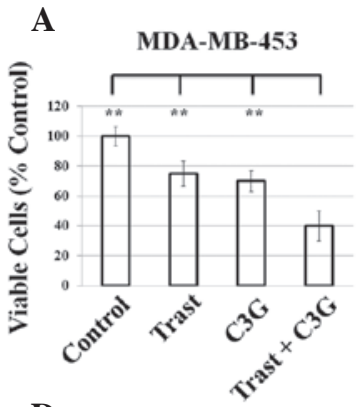

D
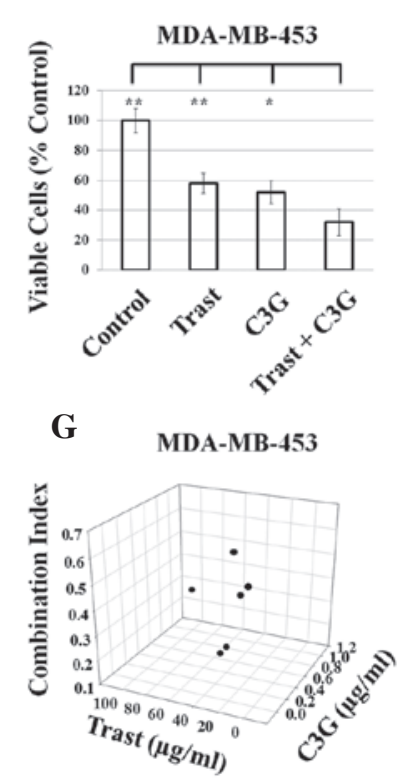

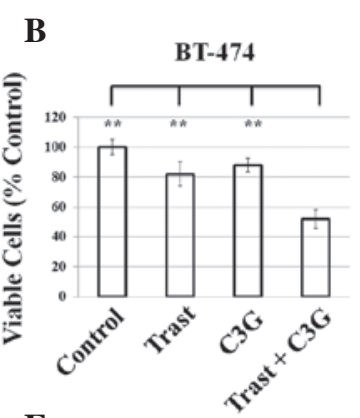

$\mathbf{E}$
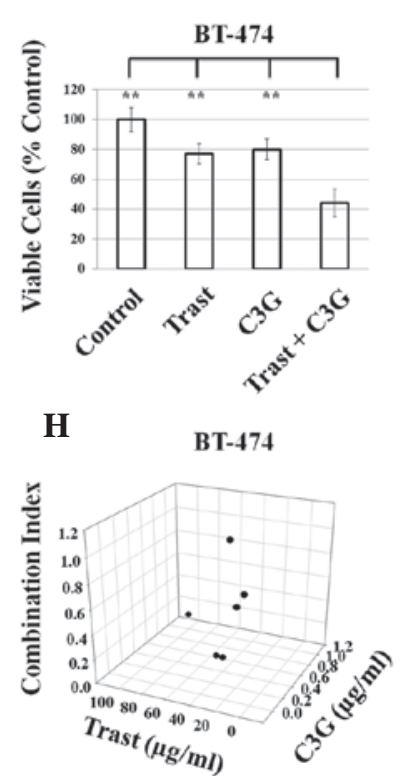

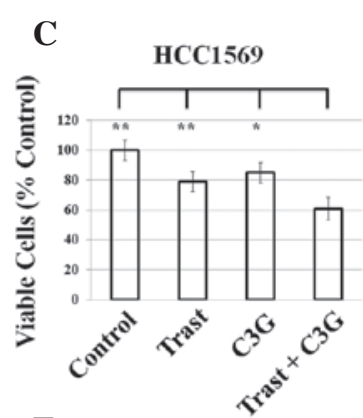

$\mathbf{F}$

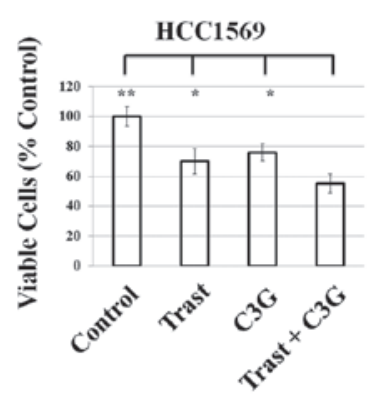

I

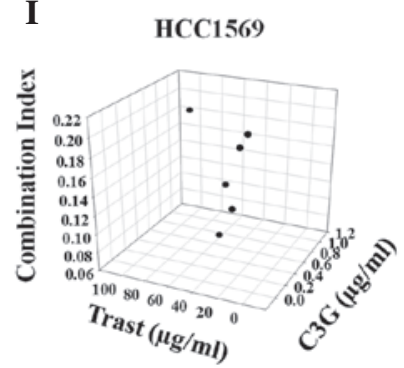

Figure 1. Effects of $\mathrm{C} 3 \mathrm{G}$ alone or in combination with Trast on the proliferation of human epidermal growth factor recepter 2-positive cell lines. BT474, MDA-MB-453 and HCC1569 cells were treated with DMSO (control), C3G $(5 \mu \mathrm{g} / \mathrm{ml})$, Trast $(5 \mu \mathrm{g} / \mathrm{ml})$ or drugs in combination (C3G and Trast) for (A-C) 24 and (D-F) $48 \mathrm{~h}$. Cell viability is presented as the percentage of viable cells vs. DMSO-treated cells. Data are expressed as the mean \pm standard deviation. ${ }^{*} \mathrm{P}<0.05,{ }^{* * *} \mathrm{P}<0.01$. (G-H) BT474, MDA-MB-453 and HCC1569 cells were treated with DMSO (control), C3G, Trast or drugs in combination (C3G and Trast) at the indicated concentrations for $72 \mathrm{~h}$. CI values were calculated using CalcuSyn. $\mathrm{CI}<1$ indicates synergism; $\mathrm{CI}=1$ indicates addictive; $\mathrm{CI}>1$ indicates antagonism. DMSO, dimethyl sulfoxide; CI, combination index; C3G, cyanidin 3-glucoside; Trast, trastuzumab.

(Fig. 1G-I; CI<1). The combination in HCC1569 cells was highly synergistic with all CI values $<0.25$ (Fig. 1I).

HER2, AKT and MAPK are central to the synergism between $C 3 G$ and Trast. To confirm that the demonstrated synergistic inhibition following treatment of $\mathrm{C} 3 \mathrm{G}$ in combination with Trast was due to HER2 inactivation, western blot analysis was performed to assess the expression levels of phospho-HER2, HER2 and its downstream mediators AKT and MAPK. As expected, the phospho-HER2, phospho-AKT (Ser473) and phospho-p44/42 MAKP levels were downregulated by C3G $(5 \mu \mathrm{g} / \mathrm{ml})$ alone and in combination with Trast (5 $\mu \mathrm{g} / \mathrm{ml}$; Fig. 2).

C3G in combination with Trast induces apoptosis in HER2-positive breast cancer cells. The activity of $\mathrm{C} 3 \mathrm{G}$ alone and in combination with Trast was determined using Annexin V and caspase 3/7 activity assays. After $24 \mathrm{~h}$ treatment, the MDA-MB-453 cells treated with Trast, $\mathrm{C} 3 \mathrm{G}$ or in combination showed $4.2 \pm 0.85,3.6 \pm 1.25$ and $11.2 \pm 2.64$ fold increases in Annexin V-positive cells compared with the control cells, respectively. After $24 \mathrm{~h}$ treatment, the BT474 cells treated with Trast, $\mathrm{C} 3 \mathrm{G}$ or in combination demonstrated $3.8 \pm 0.50,4.8 \pm 1.20$ and $13.2 \pm 2.60$ fold increases in
Annexin V-positive cells compared with the control cells, respectively. After $24 \mathrm{~h}$ treatment, the HCC1569 cells treated with Trast, $\mathrm{C} 3 \mathrm{G}$ or in combination demonstrated 4.0 \pm 1.3 , $2.1 \pm 0.32$ and $8.6 \pm 2.10$ fold increases in Annexin V-positive cells compared with the control cells, respectively. After $48 \mathrm{~h}$ treatment, the caspase 3/7 activity in MDA-MB-453 cells treated with Trast, $\mathrm{C} 3 \mathrm{G}$ alone or in combination demonstrated $4.3 \pm 1.2,6.5 \pm 1.6$ and 15.6 \pm 2.3 fold increases compared with the control cells. After 48 h treatment, the caspase 3/7 activity in BT474 cells treated with Trast, C3G alone or in combination demonstrated 5.6 $\pm 1.6,3.5 \pm 1.0$ and $10.6 \pm 3.1$ fold increases compared with the control cells. Finally, after $48 \mathrm{~h}$ treatment, the caspase 3/7 activity in HCC1569 cells treated with Trast, $\mathrm{C} 3 \mathrm{G}$ alone or in combination showed $2.1 \pm 0.9,2.8 \pm 1.3$ and 9.8 \pm 1.2 fold increases compared with the control cells (Fig. 3).

Treatment with C3G alone or in combination with Trast reduces tumor growth in vivo. Following the in vitro studies, the effects of $\mathrm{C} 3 \mathrm{G}$ treatment alone or combined with Trast were examined in a xenograft model using BT-474 cells, a HER2-positive cell line. Prior to performing studies with tumor-bearing animals, a pilot study was conducted to determine the drug tolerance at the indicated levels. Five animals 


\begin{tabular}{|c|c|c|c|}
\hline & MDA-MB-453 & BT474 & HCC1569 \\
\hline C3G & $-\quad+-+$ & -+-+ & -+-+ \\
\hline Trast & $-\quad+\quad+$ & $-\quad-\quad++$ & $-\quad+\quad+$ \\
\hline p-HER2 & - & $-\ldots+\ldots$ & $\cdots$ \\
\hline HER2 & ---- & $-\infty-\infty$ & --- \\
\hline p-AKT (Ser473) & - & -- & -- \\
\hline AKT & ---- & ---- & $--\infty$ \\
\hline p-p44/42 MAPK & $=0$ & $==$ & $=$ \\
\hline p44/42 MAPK & $=-\mathrm{a}-$ & $==$ & $=-\pi$ \\
\hline$\beta$-actin & $---\cdots$ & -500 & $-\infty-$ \\
\hline
\end{tabular}

Figure 2. Effects of C3G alone and in combination with Trast on HER2 and downstream signaling pathways. BT474, MDA-MB-453 and HCC1569 cells were treated with or without C3G $(5 \mu \mathrm{g} / \mathrm{ml})$, Trast $(5 \mu \mathrm{g} / \mathrm{ml})$ or drugs in combination for $24 \mathrm{~h}$ and whole-cell extracts were analyzed by western blotting with the indicated antibodies. C3G, cyanidin 3-glucoside; Trast, trastuzumab; HER2, human epidermal growth factor recepter 2; MAPK, mitogen-activated protein kinase.

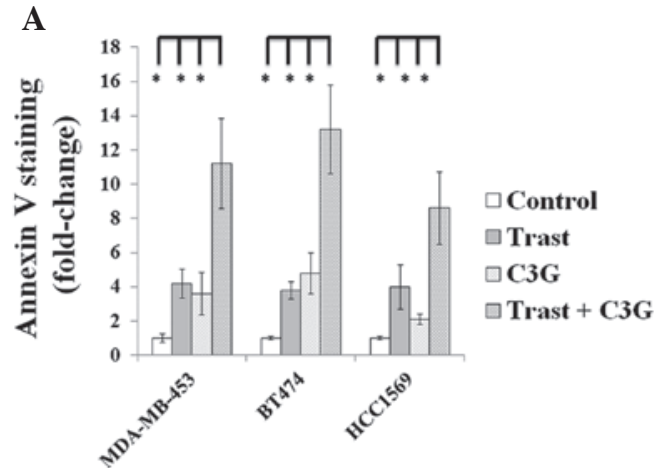

B

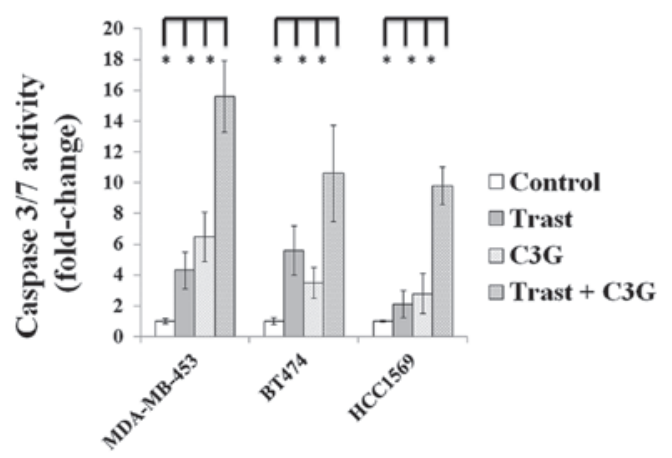

Figure 3. C3G alone and in combination with Trast induces cell apoptosis in human epidermal growth factor recepter 2-positive cell lines. Data are expressed as the mean \pm standard deviation (" $\mathrm{P}<0.01)$. (A) MDA-MB-453, BT474 and HCC1569 cells were treated with DMSO (control), Trast $(5 \mu \mathrm{g} / \mathrm{ml}$ ), C3G $(5 \mu \mathrm{g} / \mathrm{ml})$ or in combination (C3G and Trast) for $24 \mathrm{~h}$ and Annexin V positive cells were counted using flow cytometry. The fold-change in Annexin V positive cells is shown. (B) MDA-MB-453, BT474 and HCC1569 cells were treated with DMSO (control), Trast $(5 \mu \mathrm{g} / \mathrm{ml}), \mathrm{C} 3 \mathrm{G}(5 \mu \mathrm{g} / \mathrm{ml})$ or in combination (C3G and Trast) for $48 \mathrm{~h}$. The fold-change in caspase 3/7 activity is shown. Data were normalized using the following formula: caspase 3/7 activity / cell viability. C3G, cyanidin 3-glucoside; Trast, trastuzumab; DMSO, dimethyl sulfoxide. were treated with $\mathrm{C} 3 \mathrm{G}(6 \mathrm{mg} / \mathrm{ml})$ and Trast $(6 \mathrm{mg} / \mathrm{ml})$ twice a week for 25 days. No signs of organ damage were observed. The in vivo study confirmed the in vitro results. During the experiments, the body weights of the mice in the $\mathrm{C} 3 \mathrm{G}$, Trast and combination treatment group were indistinguishable from those in the control groups (Fig. 4A). Animals treated with Trast alone, $\mathrm{C} 3 \mathrm{G}$ alone or in combination demonstrated $\mathrm{a} \sim 61,41$ and $78 \%$ reduction in tumor growth (medium size) at day 25, respectively (Fig. 4B). Animals treated with Trast alone, $\mathrm{C} 3 \mathrm{G}$ alone or with the two drugs demonstrated a $\sim 54,69$ and $85 \%$ reduction in tumor weight (medium size) at day 25 , respectively (Fig. 4C).

Fig. 5A shows the hematoxylin and eosin staining of kidney, liver and spleen harvested from each treatment group. No visible damage to these organs was identified when compared with the control group (Fig. 5A). Histopathological studies revealed that tumors treated with Trast, $\mathrm{C} 3 \mathrm{G}$ or in combination expressed lower levels of HER2 and the proliferation marker Ki67 (Fig. 5B).

\section{Discussion}

Our previous studies confirmed that the pharmacological activity of $\mathrm{C} 3 \mathrm{G}$ and of $\mathrm{P} 3 \mathrm{G}$ alone in HER2-positive cell lines was mainly due to the inhibition of HER2 activity (9). The aim of the present study was to examine the synergism between $\mathrm{C} 3 \mathrm{G}$ and Trast. It has been reported that mulberry anthocyanins, cyanidin 3-rutinoside and $\mathrm{C} 3 \mathrm{G}$ inhibit the migration and invasion of human lung cancer cells (17). In addition, it has been demonstrated that $\mathrm{C} 3 \mathrm{G}$ and $\mathrm{P} 3 \mathrm{G}$ inhibit G2/M arrest, downregulate cyclin-dependent kinases and induce caspase-3 activation, chromatin condensation and cell death in vitro (18). C3G has been demonstrated to inhibit human lung tumor growth in xenograft models, including carcinoma cell A549 and 
A

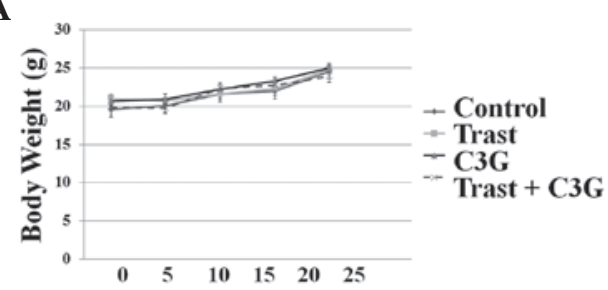

Days after treatment

B

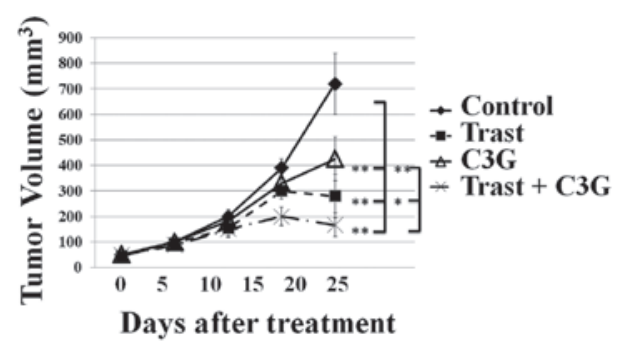

C

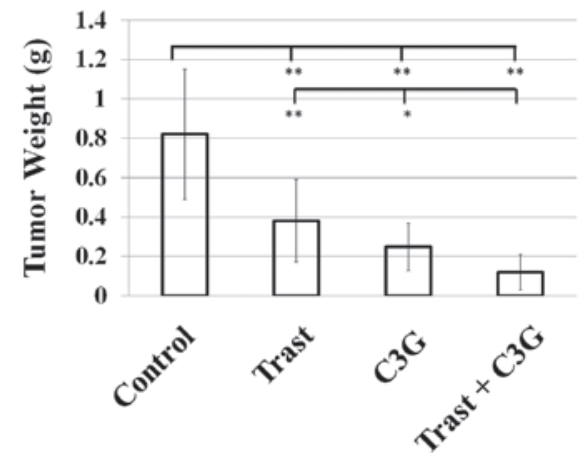

Figure 4. Antitumor effects of $\mathrm{C} 3 \mathrm{G}$ alone or in combination with Trast in a BT474 human breast cancer xenograft model. Nude mice bearing BT474 cells as xenografts were treated with either control (saline), C3G $(6 \mathrm{mg} / \mathrm{kg}$ twice weekly), Trast ( $6 \mathrm{mg} / \mathrm{kg}$ twice weekly) or with a combination of $\mathrm{C} 3 \mathrm{G}$ and Trast. Values are expressed as the mean \pm standard error of the mean $(n=10)$ $($ P $<0.05)$. (A) Body weight of animals. (B and C) Effects on tumor volume and tumor weight. $\mathrm{C} 3 \mathrm{G}$, cyanidin 3-glucoside; Trast, trastuzumab.

Lewis lung carcinoma cell tumor-bearing models $(18,19)$. C3G derived from bilberry also inhibited intestinal adenoma formation in an Apc(Min) mouse model (20). The present study was performed based on the antitumor efficacy potential of $\mathrm{C} 3 \mathrm{G}$ and P3G observed in preclinical studies $(9-11,13,14,16-20)$.

Our previous studies demonstrated that the mechanism of action of $\mathrm{C} 3 \mathrm{G}$ and $\mathrm{P} 3 \mathrm{G}$ in MDA-MB-453, BT474 and HCC1569 cells was due to the inhibition of HER2 activity. The AKT/MAPK pathway was also inhibited by $\mathrm{C} 3 \mathrm{G}$ and $\mathrm{P} 3 \mathrm{G}$ treatment in these cell lines. The previous study also demonstrated that treatment with $\mathrm{C} 3 \mathrm{G}$ or $\mathrm{P} 3 \mathrm{G}$ induced cell apoptosis and lead to cell death in vitro. In vivo experiments using an MDA-MB-453 tumor-bearing model also supported these in vitro findings (9). The data from the present study indicated that $\mathrm{C} 3 \mathrm{G}$ in combination with Trast functioned synergistically to inhibit HER2-positive cell proliferation in vitro and in vivo. However, mechanistic studies that fully explain the enhanced tumor cell death following treatments with $\mathrm{C} 3 \mathrm{G}$ in combination with Trast remain incomplete. The initial rationale for
A

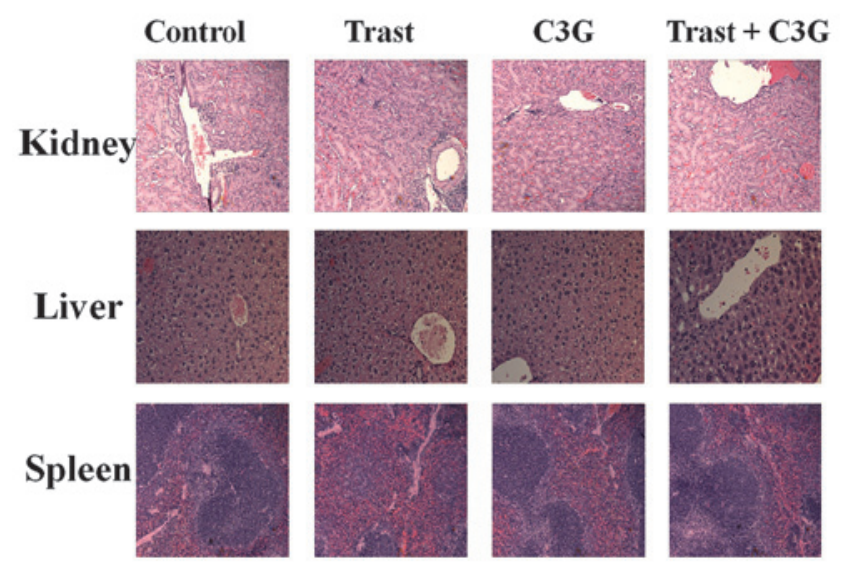

B

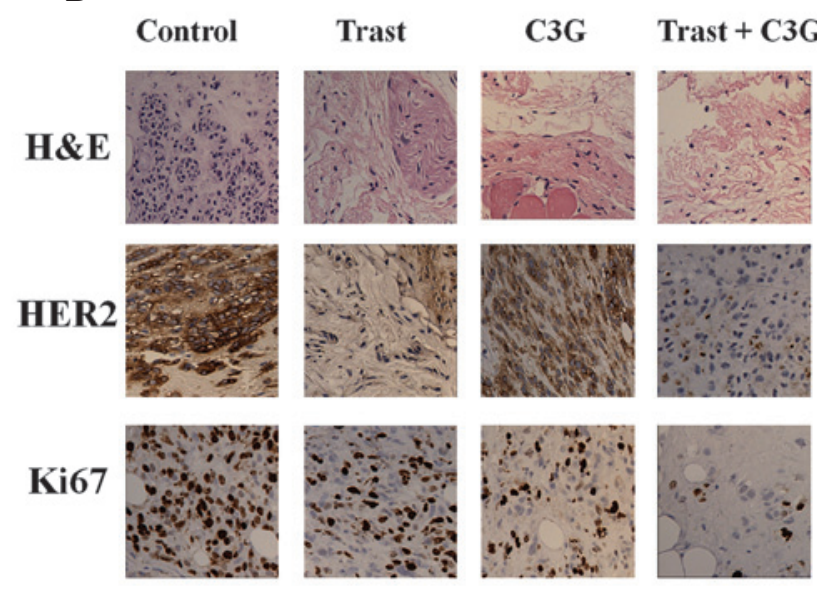

Figure 5. Antitumor effects of $\mathrm{C} 3 \mathrm{G}$ alone or in combination with Trast in a BT474 human breast cancer xenograft model. Nude mice bearing BT474 cells as xenografts were treated with either control (saline), C3G $(6 \mathrm{mg} / \mathrm{kg}$ twice weekly), Trast (6 mg/kg twice weekly) or with a combination of C3G and Trast. (A) H\&E staining for kidney, liver and spleen. (B) H\&E staining, expression of phospho-HER2 and Ki67. C3G, cyanidin 3-glucoside; Trast, trastuzumab; H\&E, hematoxylin and eosin; HER2, human epidermal growth factor recepter 2 .

the present study, following our earlier studies using $\mathrm{C} 3 \mathrm{G}$ and $\mathrm{P} 3 \mathrm{G}$, was the preferential cytotoxicity for HER2-positive cells, in conjunction with the evidence that the activity of $\mathrm{C} 3 \mathrm{G}$ and P3G in MDA-MB-453 cell-bearing mice models can be explained by reduced HER2 levels (9). The in vitro and in vivo data from the present study indicated that inhibiting HER2, AKT and MAPK activities in MDA-MB-453, BT474 and HCC 1569 cells by $\mathrm{C} 3 \mathrm{G}$ alone or in combination with Trast may be the synergistic mechanism between $\mathrm{C} 3 \mathrm{G}$ and Trast.

In conclusion, C3G significantly enhanced Trast-induced growth inhibition in representative HER2-positive cells, including MDA-MB-453, BT474 and HCC1569 cells in vitro. Treatment with $\mathrm{C} 3 \mathrm{G}$ in combination with Trast demonstrated a more potent inhibition of tumor growth in a BT474 tumor-bearing mice model compared with the control, $\mathrm{C} 3 \mathrm{G}$ alone or Trast alone treatment groups. The results of the present study provide support for further investigation to examine the therapeutic potential of anthocyanin components in combination with Trast in HER2-positive breast cancer patients and the effects of anthocyanin on Trast-resistant cells. 


\section{Acknowledgements}

The authors would like to thank the Chengdu Medical College Flow-cytometry Core Facility and the Animal Core Facility for assistance in conducting the in vitro and in vivo studies. The present study was supported by Sichuan Province Health Bureau (grant no. 110465) and by the National Natural Science Foundation of China (grant no. 81273074).

\section{References}

1. American Cancer Society: Cancer Facts \& Figures 2013. American Cancer Society, Atlanta, 2013.

2. Lv F, Yu Y, Zhang B, Liang D, Li ZM and You W: Inhibitory effects of mild hyperthermia plus docetaxel therapy on ER(+/-) breast cancer cells and action mechanisms. J Huazhong Univ Sci Technolog Med Sci 33: 870-876, 2013.

3. Vrbic S, Pejcic I, Filipovic S, Kocic B and Vrbic M: Current and future anti-HER 2 therapy in breast cancer. J BUON 18: 4-16, 2013

4. Marty M, Cognetti F, Maraninchi D, et al: Randomized phase II trial of the efficacy and safety of trastuzumab combined with docetaxel in patients with human epidermal growth factor receptor 2-positive metastatic breast cancer administered as first-line treatment: the M77001 study group. J Clin Oncol 23 : 4265-4274, 2005.

5. Neve RM, Chin K, Fridlyand J, et al: A collection of breast cancer cell lines for the study of functionally distinct cancer subtypes. Cancer Cell 10: 515-527, 2006.

6. Slamon DJ, Leyland-Jones B, Shak S, et al: Use of chemotherapy plus a monoclonal antibody against HER2 for metastatic breast cancer that overexpresses HER2. N Eng J Med 344: 783-792, 2001

7. Huang C, Lee SY, Lin CL, et al: Co-treatment with quercetin and $1,2,3,4,6$-penta-O-galloyl- $\beta$-d-glucose causes cell cycle arrest and apoptosis in human breast cancer MDA-MB-231 and AU565 cells. J Agric Food Chem 61: 6430-6445, 2013.

8. Wu XQ, Shao SJ and Qu WC: Effects of ru'ai shuhou recipe on the matrix metalloproteinases and the inhibitive factors in the recurrence and metastasis of HER2 positive breast cancer. Zhongguo Zhong Xi Yi Jie He Za Zhi Zhongguo Zhongxiyi Jie He Za Zhi 32: 1526-1530, 2012 (In Chinese).
9. Liu W, Xu J, Wu S, et al: Selective anti-proliferation of HER2-positive breast cancer cells by anthocyanins identified by high-throughput screening. PloS One 8: e81586, 2013.

10. Chen $X Q$, Nagao N, Itani T and Irifune K: Anti-oxidative analysis and identification and quantification of anthocyanin pigments in different coloured rice. Food chem 135: 2783-2788, 2012.

11. Fernandes I, Faria A, Azevedo J, et al: Influence of anthocyanins, derivative pigments and other catechol and pyrogallol-type phenolics on breast cancer cell proliferation. J Agric Food Chem 58: 3785-3792, 2010.

12. Bunea A, Rugina D, Sconta Z, et al: Anthocyanin determination in blueberry extracts from various cultivars and their antiproliferative and apoptotic properties in B16-F10 metastatic murine melanoma cells. Phytochemistry 95: 436-444, 2013.

13. Fernandes I, Marques F, de Freitas V and Mateus N: Antioxidant and antiproliferative properties of methylated metabolites of anthocyanins. Food Chem 141: 2923-2933, 2013.

14. Heinonen M: Antioxidant activity and antimicrobial effect of berry phenolics - a Finnish perspective. Mol Nutr Food Res 51: 684-691, 2007.

15. Iriti M and Varoni EM: Chemopreventive potential of flavonoids in oral squamous cell carcinoma in human studies. Nutrients 5: 2564-2576, 2013

16. Kamenickova A, Anzenbacherova E, Pavek P, et al: Effects of anthocyanins on the AhR-CYP1A1 signaling pathway in human hepatocytes and human cancer cell lines. Toxicol Lett 21: 1-8, 2013.

17. Chen PN, Chu SC, Chiou HL, Kuo WH, Chiang CL and Hsieh YS: Mulberry anthocyanins, cyanidin 3-rutinoside and cyanidin 3-glucoside, exhibited an inhibitory effect on the migration and invasion of a human lung cancer cell line. Cancer Lett 235: 248-259, 2006.

18. Chen PN, Chu SC, Chiou HL, Chiang CL, Yang SF and Hsieh YS: Cyanidin 3-glucoside and peonidin 3-glucoside inhibit tumor cell growth and induce apoptosis in vitro and suppress tumor growth in vivo. Nutr Cancer 53: 232-243, 2005.

19. Ding M, Feng R, Wang SY, et al: Cyanidin-3-glucoside, a natural product derived from blackberry, exhibits chemopreventive and chemotherapeutic activity. J Biol Chem 281: 17359-17368, 2006.

20. Cooke D, Schwarz M, Boocock D, et al: Effect of cyanidin-3-glucoside and an anthocyanin mixture from bilberry on adenoma development in the ApcMin mouse model of intestinal carcinogenesis - relationship with tissue anthocyanin levels. Int J cancer 119: 2213-2220, 2006. 